\title{
Brain-Derived Neurotrophic Factor Mediates Non-Cell-Autonomous Regulation of Sensory Neuron Position and Identity
}

\author{
Melissa A. Wright ${ }^{1,2,3}$ and Angeles B. Ribera ${ }^{1,2,3}$

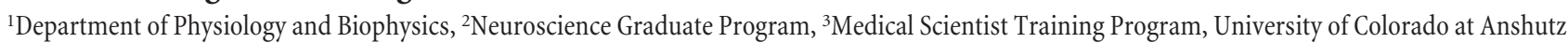 \\ Medical Center, Aurora, Colorado 80045
}

\begin{abstract}
During development, neurons migrate considerable distances to reside in locations that enable their individual functional roles. Whereas migration mechanisms have been extensively studied, much less is known about how neurons remain in their ideal locations. We sought to identify factors that maintain the position of postmigratory dorsal root ganglion neurons, neural crest derivatives for which migration and final position play an important developmental role. We found that an early developing population of sensory neurons maintains the position of later born dorsal root ganglia neurons in an activity-dependent manner. Further, inhibiting or increasing the function of brain-derived neurotrophic factor induces or prevents, respectively, migration of dorsal root ganglia neurons out of the ganglion to locations where they acquire a new identity. Overall, the results demonstrate that neurotrophins mediate non-cell-autonomous maintenance of position and thereby the identity of differentiated neurons.
\end{abstract}

\section{Introduction}

In both the peripheral nervous system and CNS, migration results in neurons acquiring positions that differ from their sites of genesis. Whereas numerous studies have investigated migration mechanisms, much less is known about factors that lead to maintenance of neuronal position after migration has occurred. Neuronal activity plays an important role in regulating many differentiated properties of neurons. On this basis, we were interested in whether activity also plays a role in maintaining the final position of neurons after migration has occurred.

Clues to mechanisms by which activity might regulate the final position of a neuron might come from the role of activity in neuronal migration. Several recent studies point to electrical activity as an important regulator of migration of embryonic neurons (Tam et al., 2000; Bolteus and Bordey, 2004; Heng et al., 2007; Tong et al., 2009). In some instances, electrical activity regulates cell migration through modulation of calcium signaling cascades (Tam et al., 2000; Tong et al., 2009). In addition, electrical activity has also been shown to regulate expression and localization of cell adhesion molecules (Pierre et al., 2001), which are important regulators of cell migration and positioning. These studies point to cell-autonomous mechanisms through which electrical activity regulates the position of developing neurons.

Received Aug. 2, 2010; revised Aug. 23, 2010; accepted Sept. 2, 2010.

The work was supported by National Institute of Neurological Disease and Stroke Grants F30NS061409 (M.A.W.), and R01NS038937 and P30NS048154 (A.B.R.). We thank Uwe Strähle for providing transgenic lines, Wallace Chick of the Transgenic and Gene Targeting Core of the Rocky Mountain Neurological Disorders Center Core for the scn8aa transgenic construct, and members of the Ribera group for comments on the manuscript.

Correspondence should be addressed to Angeles B. Ribera, Department of Physiology MS8307, UCAMC, Aurora, C0 80045. E-mail: angie.ribera@ucdenver.edu.

D0I:10.1523/JNEUROSCI.4025-10.2010

Copyright $\odot 2010$ the authors $\quad 0270-6474 / 10 / 3014513-09 \$ 15.00 / 0$
However, electrical activity also exerts non-cell-autonomous control over neuronal migration. In both the enteric nervous system (Hao et al., 2010) and the embryonic cortex (Behar et al., 2000; Bolteus and Bordey, 2004), activation of neurotransmitter receptors activate signaling cascades that regulate migration of postmitotic neurons or neuronal precursors. For these cells, electrical activity regulates migration non-cell-autonomously, through its effects on neurotransmitter release. Further, many neurotrophins, which guide migration, differentiation, and maintenance of neurons, are secreted in an activity-dependent manner (Wu et al., 2004; Bruno and Cuello, 2006; Kuczewski et al., 2009), suggesting another mechanism for non-cell-autonomous control of the position of developing neurons.

Recent work points to an important role for the voltage-gated sodium channel nav1.6a in maintenance of position of postmigratory dorsal root ganglion (DRG) neurons (Wright et al., 2010). However, DRG as well as many other neurons express the gene (scn8aa) encoding navl.6a (Novak et al., 2006), indicating that nav1.6a could act either cell-autonomously or non-cellautonomously to regulate DRG position. Here, using mosaic knock-down of nav1.6a, we determined that nav1.6a exerts noncell-autonomous control over DRG position through channel activity in early developing Rohon-Beard (RB) sensory neurons. Further, brain-derived neurotrophic factor (BDNF) rescues the DRG migration phenotype in embryos with reduced nav1.6a, whereas BDNF function-blocking antibodies induce migration of differentiated DRG neurons in control embryos. Consistent with previous work, once outside the ganglion, dorsal root ganglion neurons transdifferentiate into sympathetic neurons, indicating that position plays a key role in maintaining neuronal identity. Our present results indicate that by preventing migration of DRG neurons, BDNF maintains neuronal identity. More- 
over, when embryos are raised under conditions that minimize stimulation of $\mathrm{RB}$ neurons, migration of postmigratory DRG neurons increases, revealing that maintenance of the DRG sensory system requires early tactile input.

\section{Materials and Methods}

Animal care. Adult zebrafish (Danio rerio) were maintained at $28.5^{\circ} \mathrm{C}$ on a $10 / 14 \mathrm{~h}$ dark/light cycle in the Center for Comparative Medicine at the University of Colorado Denver and bred according to established procedures (Westerfield, 1995). The University of Colorado Committees on Use and Care of Animals approved all animal protocols. The transgenic zebrafish line $\mathrm{Tg}(-3.4$ neurog1:GFP) was kindly provided by Uwe Strähle at the University of Heidelberg (Heidelberg, Germany) (Blader et al., 2003). The macho mutant line ( $\left.m a o(l)^{t t 261 /+}\right)$ was obtained from the Tübingen Stock Center (Granato et al., 1996).

Tetrodotoxin injections. $\operatorname{Tg}(-3.4$ neurog1: GFP) embryos were raised in Embryo Media until they reached $16-19 \mathrm{~h}$ postfertilization (hpf). Embryos were then manually dechorionated and injected with either distilled water $\left(\mathrm{dH}_{2} \mathrm{O}\right)$ or tetrodotoxin (TTX) (EMD Chemicals). We used 0-500 $\mu \mathrm{M}$ for dose-response experiments and $250 \mu \mathrm{M}$ for all other experiments. We included 1\% FastGreen (SigmaAldrich) in the injection solution to allow visual tracking and confirmation of transfer of the injected solution from the yolk into the animal blastomeres. DRG position was analyzed in live embryos at 48,72 , and $96 \mathrm{hpf}$. Embryos were fixed at $96 \mathrm{hpf}$ and processed for green fluorescent protein (GFP) and HuA immunoreactivities.

Morpholino injections. Morpholino antisense oligonucleotides (morpholinos) were synthesized by Gene Tools and used to knock down navl.6a protein, as previously reported (Pineda et al., 2005, 2006). One targeted the predicted translation start methionine of nav1.6a and had 25 residues with the following sequence: 5'GGGTGCAGCCATGTTTTCATCCTGC-3'. The second morpholino (5'-ATGTGGTTTGGATCAATA-CTTACTC-3') targeted the splice junction between exons 3 and 4 . Similar results were obtained with the two different morpholinos, and we refer to them collectively as $1.6 \mathrm{mo}$. Embryos injected with $1.6 \mathrm{mo}$ are referred to as morphants throughout this article. Two control morpholinos (1.6ctl), differing from the translation-blocking or splice-blocking morpholino by five base mismatches, were synthesized. Embryos injected with either 1.6ctl are referred to as controls. Morpholinos (3-4 ng/nl) were injected into one- to two-cellstage embryos.

Mosaic embryos. Mosaic embryos were created by injecting single cells of 64-128-cell-stage wild-type or $\mathrm{Tg}(-3.4$ neurog1:GFP) embryos with $0.3 \mathrm{~mm} 1.6 \mathrm{mo}$ or $1.6 \mathrm{ctl}$ and lineage tracer (3\% lysinated-fluorescien or rhodamine-labeled dextran; molecular weight, 10,000 kDA; Invitrogen). Embryos were fixed at $72 \mathrm{hpf}$, and processed for the dextran label and either GFP or HuA immunoreactivites, as described below (Immunocytochemistry).

Generation of transient transgenics. The $5^{\prime}$ upstream region of the scn8aa gene contained within the DKEY-9P24 BAC was cloned in front of mCherry by the Transgenic and Gene Targeting Core of the Rocky Mountain Neurological Disorders Center Core at University of Colorado at Anshutz Medical Center (P30 NS048154). Transient scn8aa:mCherry transgenics were generated by injection of $100 \mathrm{ng} / \mu \mathrm{l}$ DNA along with $1.6 \mathrm{ctl}$ or $1.6 \mathrm{mo}$ and $1 \%$ FastGreen directly into the raised cell of one-cell $\mathrm{Tg}(-3.4$ neurog1:GFP) embryos.

Neurotrophin and BDNF antibody injections. Nerve growth factor (NGF) (N-130, Alomone Labs), NT3 (N-260, Alomone Labs), or BDNF
(B-250, Alomone Labs) was injected into 1.6 morphant or control $\mathrm{Tg}(-3.4$ neurog1:GFP) embryos at 16, 24, or $48 \mathrm{hpf}$ at a concentration of $50 \mathrm{ng} / \mathrm{ml}$. For dose-response experiments, BDNF $(1-500 \mathrm{ng} / \mathrm{ml})$ was injected into $48 \mathrm{hpf} \mathrm{Tg}(-3.4$ neurog1:GFP) 1.6 morphants. Chicken antiBDNF (100-1000 $\mu \mathrm{g} / \mathrm{ml}$; AF248, R\&D Systems) was injected into $48 \mathrm{hpf}$ $\mathrm{Tg}(-3.4$ neurog1:GFP) embryos. DRG position was analyzed in live $96 \mathrm{hpf}$ larvae.

Touch assays. The touch response was assessed in embryos that swam spontaneously with a normal pattern to ensure that motor deficits were not present. For each trial, the embryo was touched on the trunk with a tungsten needle and assigned a score. A score of 1 indicated a normal response (full swimming); a score of 0.5 indicated an abnormal response (twitching, but not swimming); a score of 0 indicated no response. We performed 10 trials per embryo and summed scores for each trial, resulting in final scores of $0-10$.

Sensory manipulation. Embryos raised under conditions of increased tactile stimulation were raised under normal conditions except for manual dechorionation at $16 \mathrm{hpf}$ and stimulation with a soft poker eight times a day between 16 and $96 \mathrm{hpf}$. Embryos raised under conditions of decreased tactile stimulation were raised from 16 to $96 \mathrm{hpf}$ at half density (40-50 vs $80-100$ per dish), not moved, and kept in a separate incubator that was not opened. For all groups, media was changed at $16 \mathrm{hpf}$, but not again until 96 hpf.

Immunocytochemistry. Whole-mount immunocytochemistry was performed as previously described with minor modifications (Svoboda et al., 2001). Briefly, embryos were fixed overnight $\left(4^{\circ} \mathrm{C}\right)$ with $4 \%$ paraformaldehyde in PBS solution containing 0.1\% Tween-20 (PBST). After washing with PBST, embryos were permeabilized by incubation in distilled $\mathrm{H}_{2} \mathrm{O}$, followed by exposure to $100 \%$ acetone at $-20^{\circ} \mathrm{C}$ and a final collagenase $(1 \mathrm{mg} / \mathrm{ml})$ treatment. Embryos were blocked in $10 \%$ heatinactivated goat serum/PBST and incubated overnight $\left(4^{\circ} \mathrm{C}\right)$ in $10 \%$ serum/PBST containing primary antibody. After extensive rinsing with PBST, secondary antibody was applied. Embryos were then washed in PBST, postfixed in 4\% paraformaldehyde PBS solution, and rinsed again in PBST. Anti-HuA (mouse antibody, Invitrogen) was used at 1:1000; 

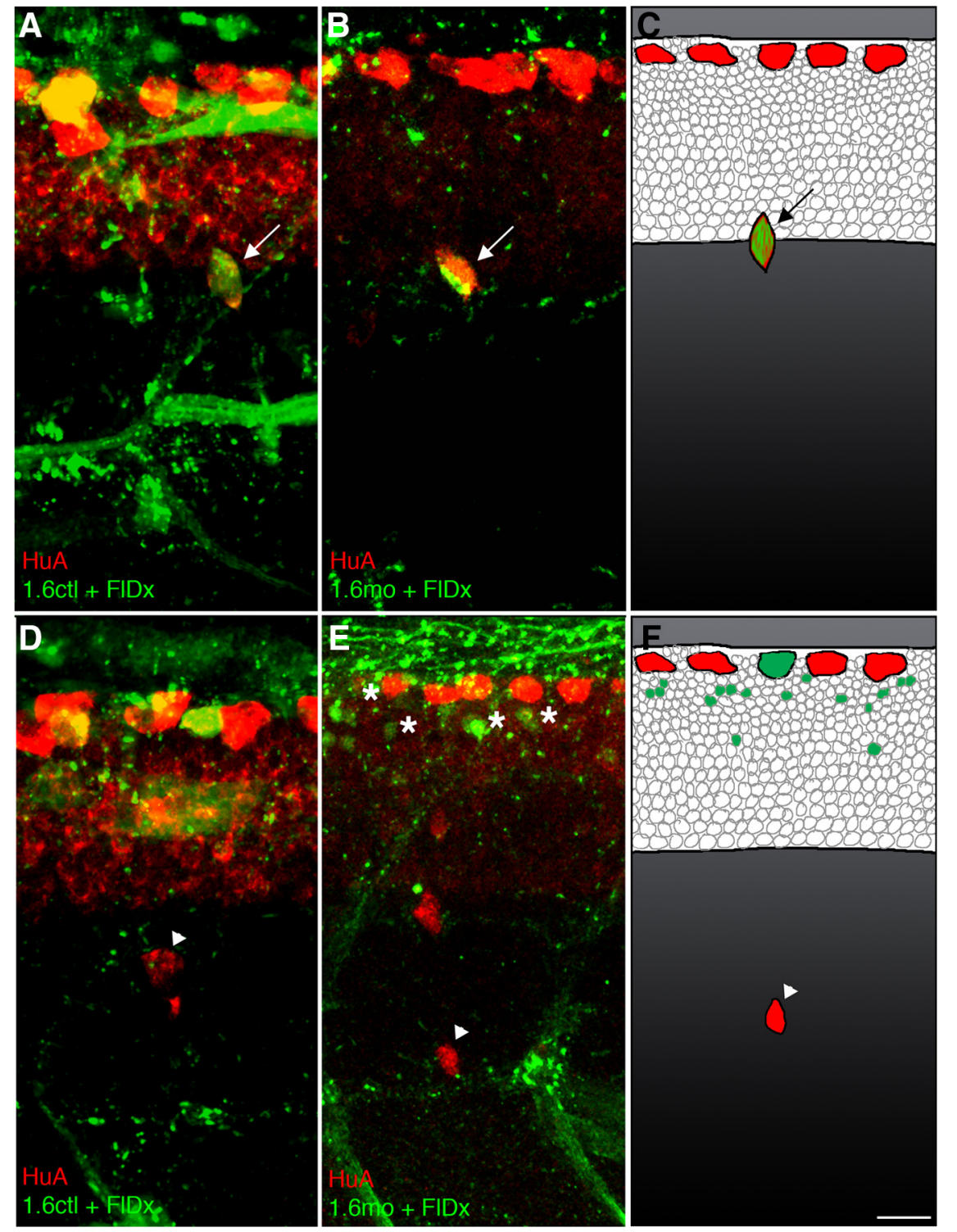

Figure 2. nav1.6a does not cell autonomously regulate maintenance of DRG position. $\boldsymbol{A}-\boldsymbol{C}$, In 3 dpf embryos, the presence of 1.6ctl ( $\boldsymbol{A})$ or 1.6mo ( $\boldsymbol{B}, \boldsymbol{C})$ in DRG neurons does not affect DRG position; HuA immunoreactivity identified DRG neurons (red, arrows). FIDx (green) was coinjected with morpholino to serve as a lineage tracer. $\boldsymbol{D}$, The rare ectopic DRG neuron (arrowhead) present in mosaic 1.6ctl embryos does not contain the FIDx. $\boldsymbol{E}, \boldsymbol{F}$, Similarly, even though there is an increase in the number of ectopic DRG neurons in mosaic $1.6 \mathrm{mo}$ embryos, the mo and tracer (green) are not found within the ectopic DRG neurons (arrowheads). Instead, the tracer is present in other spinal cord cells (asterisks). HuA immunoreactivity is normally present in dorsal RB sensory neurons, as shown in all panels. Scale bar, $10 \mu \mathrm{m}$.

anti-fluorescein or rhodamine (rabbit antibodies, Invitrogen) was used at 1:200; and goat-anti-mouse-Alexa568 and goat-anti-rabbit-Alexa568 secondary antibodies (Invitrogen) were used at 1:1000. For detection of GFP, the rabbit-anti-GFP-488 antibody (Invitrogen) was used at 1:400. For double immunocytochemistry, when used with mouse antibodies, the anti-GFP antibody was added during incubation with the secondary antibody; when used with rabbit antibodies, the anti-GFP antibody was added following extensive washing of the anti-rabbit secondary antibody.

Confocal imaging and analysis of DRG position. Confocal $z$-stacks were acquired using a Zeiss LSM5 Pascal Confocal Upright Microscope equipped with either a $10 \times$ or a $40 \times$ water-immersion lens and the pinhole set to 1 Airy unit. For analysis of DRG position in live $\mathrm{Tg}$ (-3.4neurog1:GFP) embryos, specimens were mounted laterally in a drop of $0.5 \%$ low-melting-point agarose containing $0.0002 \%$ tricaine (Sigma-Aldrich). DRG position was analyzed throughout the length of the embryo. GFP ${ }^{+}$DRG cells were considered to be ectopic if they resided more than one cell body ventral to the spinal cord-notochord boundary.

Statistical analysis. All statistical analyses were performed using InStat3 software (GraphPad Software). Contingency tables were analyzed using Fisher's exact test to determine two-sided $p$ values. The specific tests used for other analyses depended upon whether the data were normally distributed (e.g., Student's $t$ test or ANOVA parametric tests) or not (e.g., nonparametric Mann-Whitney and KruskalWallis tests) and are indicated in the text. For data analyzed for statistical significance with nonparametric tests, the graphs present the median with the inner quartiles, 5th and 95th percentiles, and any outliers (filled circles).

\section{Results}

Sodium current is required for maintenance of DRG position

Knock-down of the nav1.6a sodium channel protein increases the number of DRG neurons that migrate out of the ganglia to more ventral positions (Wright et al., 2010). To test whether loss of sodium channel activity, rather than other effects of sodium channel protein, induces DRG migration, we blocked sodium channels pharmacologically with the sodium channel inhibitor TTX. We used a transgenic line expressing GFP under the control of a portion of the neurogenin 1 (neurog1) promoter, because neural crest expression of neurog1 leads to a neuronal fate (McGraw et al., 2008). In control $\operatorname{Tg}(-3.4$ neurog 1 : GFP) embryos, the majority of $\mathrm{GFP}^{+}$ DRG neurons showed stereotypic positions at the spinal cord-notochord boundary, with only one to two ectopic DRG cells per embryo (Fig. $1 A, C$ ). Upon injection of TTX, the number of ectopic $\mathrm{GFP}^{+}$DRG cells increased in a dosedependent manner, reaching maximal effect at $250 \mu \mathrm{M}$ (Fig. $1 B, C)$. These results indicate that loss of sodium channel activity promotes migration of cells away from the dorsal root ganglia.

The number of ectopic DRG cells in TTX-injected embryos increased after $3 \mathrm{~d}$ postfertilization (dpf) (data not shown), as would be expected if DRG neurons migrate after differentiating. To test directly whether the ectopic DRG cells that develop in TTX-injected larvae are differentiated neurons, we examined expression of the neuronal differentiation marker, HuA. Ectopic $\mathrm{GFP}^{+}$cells in both control and TTX-injected larvae expressed HuA (Fig. $1 D, E)$. Together, these data indicate that sodium channel inactivity increases the number of migratory differentiated DRG neurons in zebrafish larvae.

\section{RB sodium current prevents ventral migration of DRG neurons}

TTX injection affects sodium channels throughout the embryo (Fig. 1), preventing determination of the location and identity of 
the relevant sodium channels. However, previous work implicated the nav1.6a sodium channel encoded by the scn8aa gene (Wright et al., 2010). Nonetheless, developing DRG neurons as well as other neurons express scn8aa, leaving the location of the relevant sodium channels an open question. To identify the cell type expressing the relevant sodium channels, we generated embryos that had mosaic knock-down of nav1.6a by injecting well characterized antisense morpholinos targeting scn8aa (1.6mo; Pineda et al., 2005; Pineda et al., 2006) into single cells of 64-cellstage embryos (Fig. $2 B, C, E, F$ ). At $72 \mathrm{hpf}$, we immunostained embryos for the coinjected lineage tracer rhodamine dextran and $\mathrm{HuA}$ to determine the relationship between DRG position and morpholino distribution (Figs. 2, 3).

Embryos mosaic for $1.6 \mathrm{mo}$ (Fig. $2 B, C, E, F$ ) showed a small increase in the number of migratory DRG neurons compared with $1.6 \mathrm{ctl}$ mosaic embryos (Fig. $2 A, D)$ ( 1.56 vs $0.58,1.6 \mathrm{mo}$ vs $1.6 \mathrm{ctl}$, respectively; $p<0.0001$, Mann-Whitney $U$ test). This finding demonstrates that mosaic knock-down of nav1.6a suffices to induce ventral migration of DRG neurons (Fig. $2 E, F$ ). However, $<1 \%$ of ectopic DRGs in 1.6mo mosaic embryos were positive for the fluorescent tracer. In contrast, $96 \%$ of DRGs that contained the morpholino were normally positioned (Fig. $2 B, C)(p<0.0001$, Fisher's exact test). Together, these data do not support the DRG as the location of the relevant sodium channels, making a cell-autonomous requirement for nav1.6a in DRG neurons an unlikely possibility.

We next analyzed DRG position and the tracer distribution in 1.6 mo mosaic embryos. DRG position was not affected by the presence of $1.6 \mathrm{mo}$ in motor neurons, intermediate interneurons, or dorsal interneurons (data not shown). However, embryos that contained fluorescent tracer-positive RB sensory neurons showed a significant increase in the number of migratory DRG neurons compared with embryos having fluorescent tracernegative RB sensory neurons (2.7 vs 1.5 , respectively; $p=0.02$, Mann-Whitney $U$ test) (Fig. $3 A, B)$. These data indicate that nav1.6a maintains DRG position non-cell-autonomously via activity in RB cells.

The above results predict that other manipulations that reduce sodium current in RB cells will also increase the number of migratory DRG neurons. The previously characterized macho (mao) mutant has reduced sodium current density in RB cells (Ribera and Nüsslein-Volhard, 1998). As predicted, 4 dpf mao mutants have an increased number of migratory DRG neurons compared with siblings (6.9 vs 3.6, respectively; $p<0.0001$, MannWhitney $U$ test) (Fig. $3 C$ ). These findings further support the hypothesis that maintenance of DRG position within the ganglia requires sodium current in $\mathrm{RB}$ neurons.

\section{RB and DRG peripheral arbors overlap}

Although RB and DRG somata reside in different locations, both neurons innervate the skin, implicating their cutaneous peripheral arbors as a possible site of interaction. RB neurons extend processes that innervate the skin around $1 \mathrm{dpf}$, but the majority subsequently retract their processes and die before $5 \mathrm{dpf}$ (Williams et al., 2000; Reyes et al., 2004). The timing of axogenesis varies for individual DRG neurons but begins by $2 \mathrm{dpf}$ (Williams et al., 2000; An et al., 2002). Further, DRG neurons do not migrate ventrally in embryos injected with TTX or in 1.6 morphants until 2-3 dpf, stages when their axons have reached the periphery (Wright et al., 2010) (data not shown). These considerations support the possibility of an activity-dependent interaction between DRG and RB peripheral processes. However, it is not known whether RB and DRG peripheral arbors overlap before the $\mathrm{RB}$ processes retract.
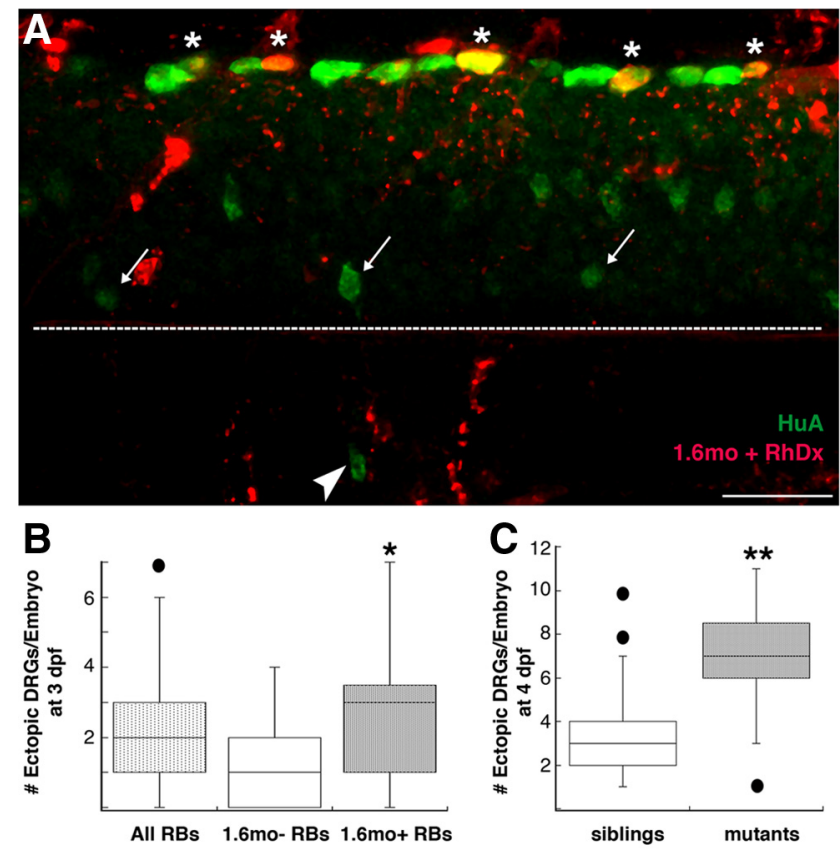

Figure 3. Maintenance of DRG position/identity requires nav1.6a in RB cells. $\boldsymbol{A}, \boldsymbol{B}$, Ectopic DRG neurons (arrowhead), identified by HuA immunoreactivity (green), were present in mosaic embryos that contained RB cells (asterisks) with $1.6 \mathrm{mo}+\mathrm{RB}$ cells (red; yellow when copresent with HuA green signal). Arrows denote normally positioned DRG neurons; the dashed white line indicates the spinal cord-notochord boundary. $\boldsymbol{B}$, The number of ectopic DRG neurons increased in mosaic embryos that contained $1.6 \mathrm{mo}$ in RB cells compared with mosaic embryos that did not contain $1.6 \mathrm{mo}$ in RB cells $\left({ }^{*} p=0.02\right.$, Mann-Whitney $U$ test; $n=44$ embryos containing $1.6 \mathrm{mo}$ in RB cells, 22 embryos not containing $1.6 \mathrm{mo}$ in RB cells). C, mao mutants, characterized by reduced sodium current densities in RB cells (Ribera and Nüsslein-Volhard, 1998), have an increased number of ectopic DRG neurons versus sibling control embryos at $4 \mathrm{dpf}$ $\left({ }^{* *} p<0.0001\right.$ vs mao siblings, Mann-Whitney $U$ test; $n=43$ mao mutant and 99 sibling embryos). Scale bar, $25 \mu \mathrm{m}$.

We determined whether DRG and RB peripheral processes overlap by expressing two different fluorescent proteins in their peripheral arbors. In $\mathrm{Tg}(-3.4$ neurog1:GFP) larvae, both RB and DRG processes express GFP, making it difficult to distinguish one from the other in the periphery. To reliably identify RB processes, we generated a transgenic construct that drives expression of another fluorescent protein (mCherry) in RB cells. We isolated a portion of the $5^{\prime}$ upstream region of the scn8aa gene and used it to transgenically drive expression of mCherry (supplemental Fig. 1, available at www.jneurosci.org as supplemental material), because RB cells show particularly robust scn8aa expression (Novak et al., 2006). We identified 1.6 control and morphant $\mathrm{Tg}(-3.4$ neurog1:GFP) embryos expressing GFP in both RB and DRG neurons, but mCherry in RB, but not DRG, neurons. For both 1.6 control and morphant embryos, tracings of individual DRG neuron processes indicated that many DRG processes reach the skin by $3 \mathrm{dpf}$ (Fig. $4 B, D$ ). Further, in both controls and morphants, DRG processes in the skin overlapped with mCherry-expressing $\mathrm{RB}$ processes. These results further support the peripheral arbors as a potential site for activity-dependent interaction between RB and DRG neurons.

\section{BDNF prevents ventral migration of DRG neurons}

The finding that sodium channel activity as well as protein is required for maintenance of DRG position raises the possibility that the relevant signal is released from RB cells in an activity- 

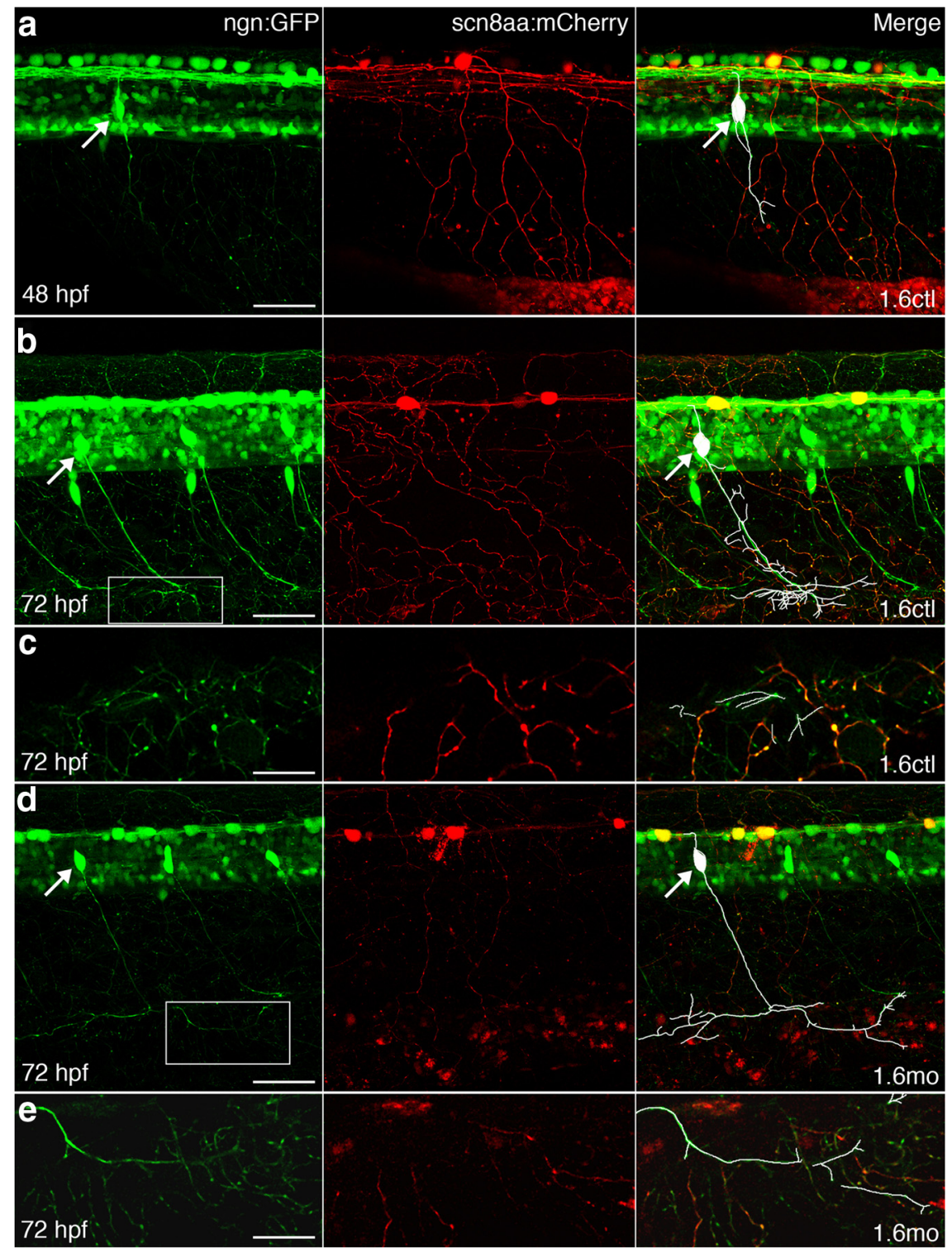

Figure 4. RB and DRG peripheral arbors overlap by $72 \mathrm{hpf}$ in 1.6 control and morphant embryos. $\boldsymbol{a}-\boldsymbol{e}, \mathrm{GFP}$ (green) in $\mathrm{Tg}(-3.4$ neurog1:GFP) embryos labels both RB and DRG axons and cell bodies, whereas stochastic labeling with mCherry allows visualization of peripheral arbors (red) of individual RB cells. In the left merged panels, white traces the processes of the DRG neuron. White arrows indicate cell bodies of DRG neurons. $\boldsymbol{a}$, In $48 \mathrm{hpf}$ embryos injected with 1.6ctl, DRG axons that run next to the notochord have not yet reached the periphery and do not overlap with cutaneous RB peripheral processes. $\boldsymbol{b}-\boldsymbol{e}$, By $72 \mathrm{hpf}$, in embryos injected with either $1.6 \mathrm{ctl}(\boldsymbol{b}, \boldsymbol{c})$ or $1.6 \mathrm{mo}(\boldsymbol{d}, \boldsymbol{e}), \mathrm{DRG}$ neurons extend processes into the skin where they overlap with RB cutaneous processes. $\mathbf{c}$ and $\boldsymbol{e}$ show $8 \mu \mathrm{m}$ confocal slices of the regions boxed in $\boldsymbol{b}$ and $\boldsymbol{d}$, respectively. Scale bars: $\boldsymbol{a}, \boldsymbol{b}, \boldsymbol{d}, 50 \mu \mathrm{m}$; $c, e, 20 \mu \mathrm{m}$.

dependent manner. Neurotrophins, which mediate nervous system development and function, are secreted in an activitydependent manner and function in the skin (for review, see Bothwell, 1997; Schinder and Poo, 2000; Wu et al., 2004). Further, various aspects of RB and DRG development require NGF, NT-3, or BDNF (Lefcort et al., 1996; Patel et al., 2000; Williams et al., 2000; Heinrich and Pagtakhan, 2004; Hapner et al., 2006; ValdésSánchez et al., 2010). Accordingly, we tested the ability of these neurotrophins to prevent migration of DRG neurons away from the ganglia in 1.6 morphants (Fig. 5). We injected NGF, NT-3, or BDNF into 1.6 morphant $\mathrm{Tg}(-3.4$ neurog1:GFP) embryos at 16 hpf-when RB neurons are just starting to elaborate arbors-28 hpf-when RB neurons have established peripheral arbors but
DRG neurons have not yet differentiated-or $48 \mathrm{hpf}$ - when DRG neurons are growing axons.

NGF and NT-3 did not significantly affect DRG migration, regardless of the time of injection (Fig. 5). In contrast, BDNF rescued the DRG phenotype of 1.6 morphants, consistent with RB cells signaling to DRG neurons through activitydependent release of BDNF (Fig. 5A). Further, if BDNF were required before 48 hpf, the results from embryos injected at 16 or 28 hpf would have differed from those injected at 48 hpf. However, the effect of BDNF on DRG position was not significantly different between embryos injected at 16, 24, or $48 \mathrm{hpf}$. This finding suggests that DRGs require BDNF after 48 hpf. At 48 hpf, nav1.6a already functions in RB cells (Pineda et al., 2005), but DRG peripheral processes first reach the skin.

Neurotrophins also modulate and possibly activate ion channels (Lesser et al., 1997; Blum et al., 2002; Ahn et al., 2007) (for review, see Luther and Birren, 2009), raising the alternative possibility that the effects of neurotrophin injection may be due to potentiation or activation of $\mathrm{RB}$ sodium current in morphants. However, this possibility is unlikely given that none of the neurotrophins tested rescued the touch response phenotype in 1.6 morphants, suggesting that nav1.6a sodium current remained impaired after neurotrophin treatment (supplemental Fig. 2A, available at www.jneurosci.org as supplemental material).

If DRG migration in 1.6 morphants resulted from decreased release of BDNF by RB cells, inhibiting BDNF actions by other means would be expected to induce migration of DRG neurons away from the ganglia in wild-type zebrafish. To test this, we injected $48 \mathrm{hpf}$ wild-type $\operatorname{Tg}(-3.4$ neurog1:GFP) embryos with a function-blocking anti-BDNF antibody. The anti-BDNF antibody increased migration of DRG neurons in a dose-dependent manner (Fig. 5B). Similar to neurotrophin injection, the anti-BDNF antibody did not affect the touch response of $60 \mathrm{hpf}$ embryos (supplemental Fig. $2 B$, available at www.jneurosci.org as supplemental material), making it unlikely that the anti-BDNF antibody affected DRG position by reducing sodium current in RB cells. Together, these data suggest that DRG neurons migrate away from the ganglia in 1.6 morphants due to a reduction in activity-dependent release of BNDF by RB neurons.

\section{Decreased tactile stimulation increases migratory DRG neurons in wild-type zebrafish}

Our studies indicate that genetic or pharmacologic reduction of sodium current in RB cells increases the frequency of migration of DRG neurons away from the ganglia. Such reductions in so- 
dium current, however, were produced by experimental perturbations not likely to be experienced by wild-type embryos. RB cells are mechanosensory neurons that are electrically activated in response to tactile stimulation during early development (Clarke et al., 1984). To determine whether environmentally induced variations in RB activity also suffice to modulate migration of DRG neurons, we raised wild-type embryos to 4 dpf under conditions of varying tactile stimulation.

Embryos raised under conditions of increased tactile stimulation did not vary from controls with respect to either touch response or the number of migratory DRG neurons (Fig. 6A,B). In sharp contrast, embryos raised under conditions that minimize tactile stimulation showed a variety of phenotypes. Approximately $20 \%$ of sensory-deprived embryos failed to hatch by $4 \mathrm{dpf}$, whereas wild-type embryos typically do so by $2 \mathrm{dpf}$ (data not shown). Further, embryos that hatched displayed a statistically significant reduction in touch sensitivity compared with embryos that received tactile stimulation (Fig. 6A) (average touch response score, 6.4 vs 8.7 , respectively; $p<0.0001$, MannWhitney $U$ test). Moreover, the number of migratory DRGs increased in sensorydeprived embryos compared with embryos raised under control conditions (Fig. 6B) (4.0 vs 2.5 migratory DRGs, respectively; $p=0.02$, Mann-Whitney $U$ test).

In nav1.6 morphant or mutant embryos, migratory DRG neurons transdifferentiate into sympathetic neurons (Wright et al., 2010). To test whether migratory DRG neurons in sensory-deprived larvae also transdifferentiate, we allowed them to develop to $11 \mathrm{dpf}$, a time when the sympathetic nervous system has differentiated. We then examined expression of HuA (a marker of both DRG and sympathetic neurons) and tyrosine hydroxylase (TH), which labels sympathetic neurons but not DRG neurons at the stages examined in this study (Wright et al., 2010). THexpressing migratory DRG neurons were present in larvae raised under conditions of decreased tactile stimulation (Fig. 6C). These data suggest that maintenance of DRG position and identity requires early tactile stimulation.

\section{Discussion}

In many systems, target-derived neurotrophins serve to match the level of innervation with the size or need of the target tissue (for review, see Purves et al., 1988; Davies, 1996). Our results suggest that neurotrophins also match the size of the sensory neuron pool to the level of early sensory stimulation. Under control conditions, activity-dependent release of BDNF from RB
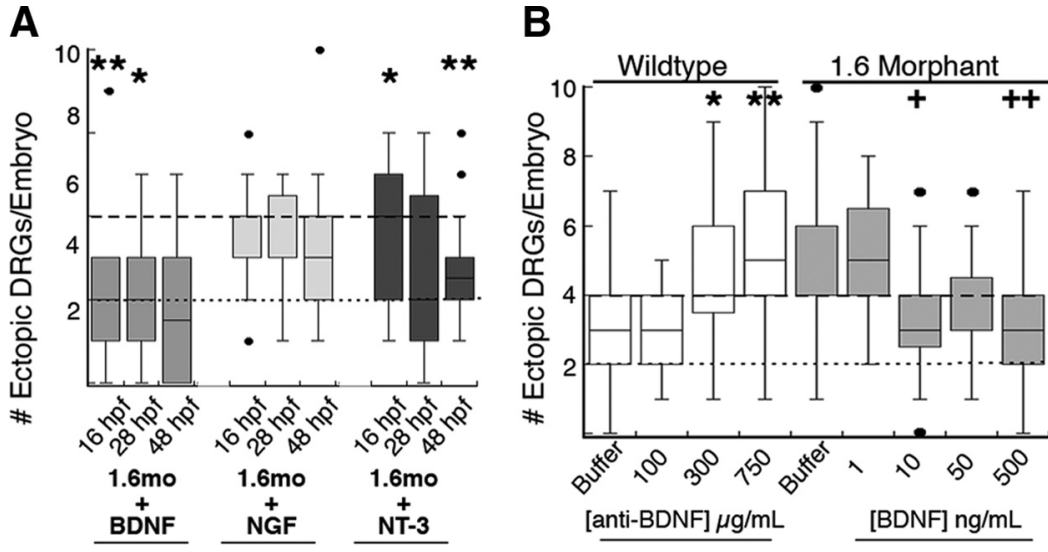

Figure 5. Maintenance of DRG identity requires BDNF. $A$, Injection of NGF $(50 \mathrm{ng} / \mathrm{ml})$ does not prevent the increase in migratory DRG neurons present in nav1.6 morphants (dashed black line). In contrast, injection of BDNF or NT-3 reduces the number of migratory DRG neurons in nav1.6 morphants to levels found in wild-type embryos (dotted black line). ${ }^{*} p<0.05,{ }^{* *} p<0.01$ versus nav1.6 morphants without neurotrophin injection, Kruskal-Wallis test; sample size ranged between 28 and 63 embryos. $\boldsymbol{B}$, Anti-BDNF injected at $48 \mathrm{hpf}$ (white bars) increases the number of migratory DRG neurons in wild-type embryos. Conversely, injection of $10-500 \mathrm{ng} / \mathrm{ml}$ BDNF reduces the number of migratory DRG neurons in nav1.6 morphants. ${ }^{*} p<0.05,{ }^{* *} p<0.01$ versus wild-type embryos injected with buffer only; ${ }^{+} p<0.05,{ }^{++} p<0.01$ versus nav1.6 morphants injected with buffer only; nonparametric Kruskal-Wallis test; sample size ranged between 13 and 34 embryos.

A
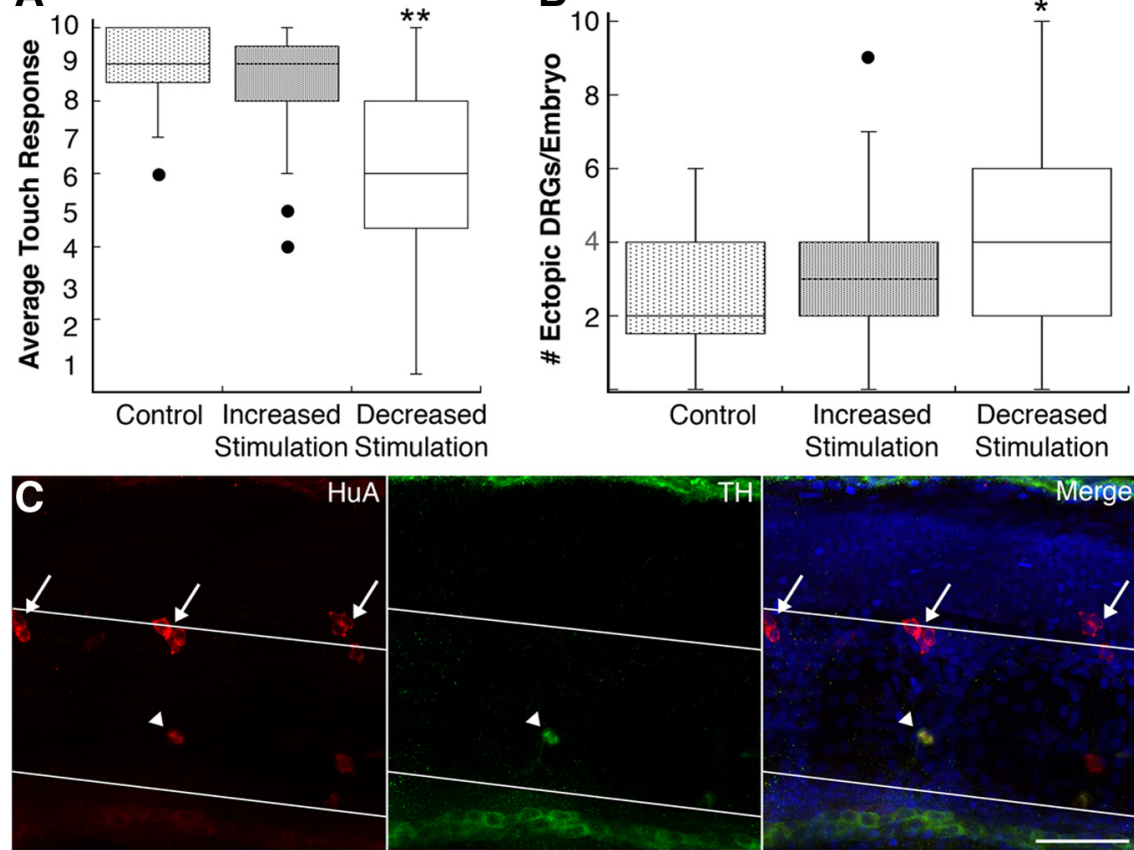

Figure 6. Decreased tactile stimulation leads to ventral migration and transdifferentiation of DRG neurons. $\boldsymbol{A}$, The $4 \mathrm{dpf}$ embryos raised under conditions that decrease tactile stimulation show a reduced touch response compared with embryos raised under control or increased stimulation conditions ${ }^{* *} p<0.001$ vs control and increased stimulation, Kruskal-Wallis; sample size ranged between 10 and 65 embryos). $\boldsymbol{B}$, Decreased tactile stimulation increases the number of ectopic DRG neurons at $4 \mathrm{dpf}\left({ }^{*} p=\right.$ 0.02 vs control, Mann-Whitney $U$ test; sample size ranged between 20 and 50 embryos). C, At $11 \mathrm{dpf}$, a subset of migratory DRG neurons (arrowhead) expresses the sympathetic marker TH (green). HuA immunoreactivity is shown in red; white lines demarcate the dorsal and ventral boundaries of the notochord; arrows indicate normally positioned DRG neurons. The fraction of migratory DRG neurons expressing TH does not differ significantly between control (9/35; 14 embryos), increased stimulation $(17 / 58 ; 16$ embryos), and sensory-deprived embryos (16/47; 13 embryos). Scale bar, $40 \mu \mathrm{m}$.

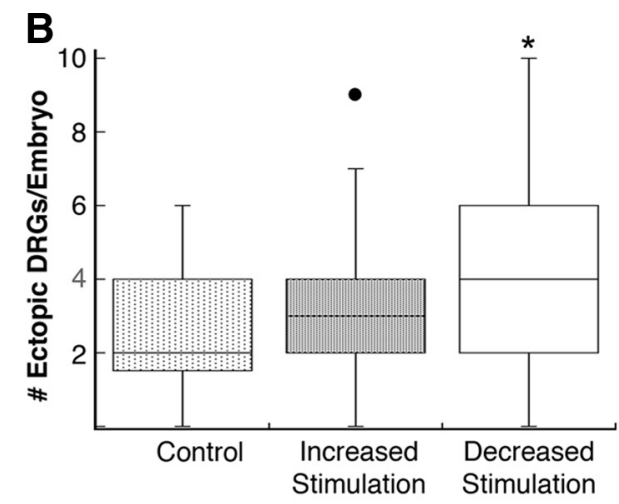

cells transduces the early sensory requirements of the embryo into a signal that maintains DRG neurons within the ganglia. In this way, BDNF regulates the number of sensory neurons that respond to touch.

We propose that sensory deprivation reduces activitydependent release of BDNF by RB cells (Figs. 6, 7). We did not 


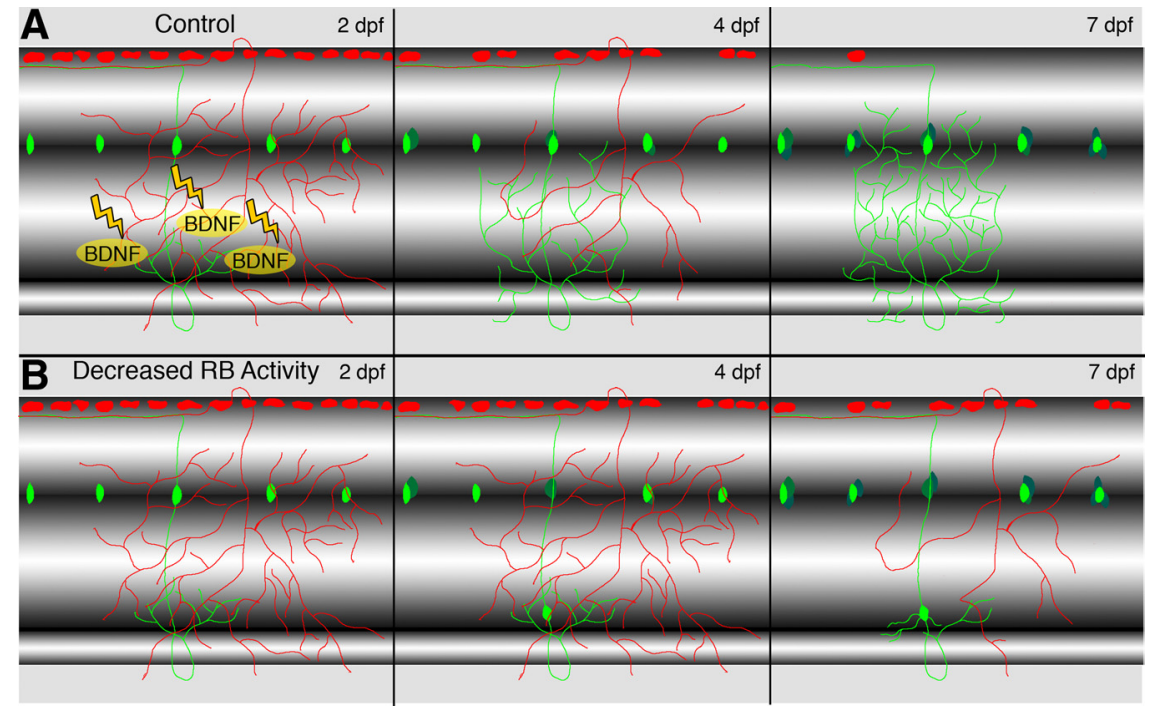

Figure 7. Model for non-cell-autonomous and activity-dependent regulation of DRG position and identity. A, At 2-3 dpf, RB (red) and DRG (green) peripheral processes overlap in the skin. Electrical stimulation in RB cells increases release of BDNF, which promotes maintenance of DRG neurons. Between 2 and $7 \mathrm{dpf}$, RB cells undergo cell death, while the number of DRG neurons increases and DRG peripheral processes elaborate. $\boldsymbol{B}$, When RB activity is reduced genetically, pharmacologically, or environmentally, BDNF release decreases and RB cells survive to later stages. The absence of BDNF triggers migration of differentiated DRG neurons between 2 and $4 \mathrm{dpf}$. At later stages (7 dpf), migratory DRG neurons adopt sympathetic neuron characteristics.

detect any obvious effects of BDNF on channel function as noted by others (supplemental Fig. $2 \mathrm{~A}$, available at www.jneurosci.org as supplemental material) (Lesser et al., 1997; Blum et al., 2002; Ahn et al., 2007) (for review, see Luther and Birren, 2009). In the absence of RB activity-dependent release of BDNF, differentiated DRG neurons migrate out of the ganglion to locations where they can transdifferentiate into, for example, sympathetic ganglia neurons (Wright et al., 2010). Further, sensory deprivation not only increases DRG migration but also significantly reduces the ability to respond to touch at later times (Fig. 4), indicating an essential requirement for activation of early sensory neurons for later sensory function.

Although activity perturbations had statistically significant effects on the number of migratory DRG neurons present in larvae, the total increase in the number of such cells per embryo was not large (e.g., a few per embryo). This finding suggests that only a subset of DRG neurons responds to sensory deprivation/BDNF loss by migrating out of the ganglion. One possible explanation is that not all DRG neurons express a receptor for BDNF such as trkB. The zebrafish genome contains two different trkB genes (Martin et al., 1995). Toward the end of gastrulation, the zebrafish embryo begins to express mRNA encoding a full-length trkB isoform (Lum et al., 2001). Expression of trkB by zebrafish DRG neurons has not yet been examined. However, in mammals a specific DRG subpopulation expresses mRNA for trkB (Wright and Snider, 1995). In addition, this subpopulation coexpresses mRNA for an alternate, albeit less selective, BDNF receptor, p75 (Wright and Snider, 1995). Many other DRG neurons also express p75, indicating that trkB, in contrast to $\mathrm{p} 75$, expression identifies a smaller subpopulation of DRG neurons.

Previous studies have revealed the importance of BDNF for DRG neurons. For example, several studies point to a key role for BDNF as a target-derived survival factor for sensory neurons (e.g., Liebl et al., 1997; Valdés-Sánchez et al., 2010) (but see Huber et al., 2000) (for review, see Barde, 1994). Further, LeMaster et al. (1999) tested the effects of BDNF overexpression in the skin; cutaneous overexpression of BDNF regulated sensory innerva- tion of the skin, revealing a role for this neurotrophin in morphological development. In addition, Carroll et al. (1998) found that slowly adapting mechanoreceptors require $\mathrm{BDNF}$ for proper development of receptive properties. Adding to this list, our studies reveal a new role for BDNF as a regulator of DRG neuron position and identity.

We found that RB cell activity plays a critical early role in establishment of the DRG sensory system. RB cells are an enigmatic population of sensory neurons that develops during the earliest stages of neurogenesis (Lamborghini, 1980; Metcalfe et al., 1990). For the most part, RB cells die during larval stages (Humphrey, 1950; Kollros and Bovbjerg, 1997; Lamborghini, 1987; Williams et al., 2000; Coen et al., 2001; Svoboda et al., 2001; Reyes et al., 2004). In this way, RB cells are reminiscent of another transient population, Cajal-Retzius cells, that plays a critical role in layer formation in the cerebral cortex. In amphibia and teleosts, RB cells form the initial sensory system of the developing embryo and are responsible for touchmediated reflexes (Clarke et al., 1984; Douglass et al., 2008). Although it is typically thought that mammals lack RB cells (but see, Humphrey, 1950), such a conclusion requires further study of embryonic stages when these cells typically are present in other vertebrates.

However, if mammals lack RBs, would the mechanism we report here be relevant to humans? The diverse DRG population in mammals arises during different waves of neurogenesis (Lawson and Biscoe, 1979), allowing the possibility of earlier born sensory neurons to regulate the fate of later-born ones (Ma et al., 1999). Further, studies in rats indicate that proper functioning of the adult nociceptive circuit requires tactile stimulation during the neonatal period (Petersson et al., 2004; Fitzgerald, 2005). Similarly, adult rats that did not receive sensory inputs from their whiskers during neonatal development perform poorly on tactile discrimination tasks (Carvell and Simons, 1996). Particularly compelling are studies indicating that children who lived in institutionalized environments with minimal sensory stimulation as infants show persisting defects in sensory discrimination and processing (Cermak and Daunhauer, 1997; Lin et al., 2005).

In our studies, DRG neurons migrate away from the ganglion between 2 and $4 \mathrm{dpf}$, following normal hatching stages. This finding supports the idea of a sensitive period during which differentiated DRG neurons are responsive to environmental cues that regulate DRG neuron number by maintenance or loss of position within the ganglion. It is currently unknown whether other sensitive periods exist when DRG neurons could be induced to migrate and transdifferentiate. However, several findings suggest the possibility of a sensitive period for DRG neuron maintenance following nerve injury. DRG neurons acquire BDNF dependency (Sebert and Shooter, 1993; Li et al., 2009; Geremia et al., 2010) and upregulate the BDNF-responsive trkB receptor following peripheral nerve injury (Sebert and Shooter, 1993); BDNF upregulation within the DRG appears to be crucial for sensory neuron regeneration (Li et al., 2009; Geremia et al., 2010). To date, it has not been tested whether DRG neurons that fail to receive trophic 
support following nerve injury migrate away from the ganglion and transdifferentiate into sympathetic neurons. However, novel sprouting of sympathetic fibers within the DRG occurs after nerve injury; the nerve sprouting is correlated with the generation of neuropathic pain (Kim et al., 1999; Shinder et al., 1999; Chung and Chung, 2001; Chien et al., 2005; Zhang and Strong, 2008). In zebrafish, migratory DRG neurons retain their dorsal axons upon transdifferentiating into sympathetic neurons (Wright et al., 2010), suggesting a possible source for sympathetic sprouting within the DRG.

The present work identifies BDNF as a factor that maintains the position and identity of differentiated DRG neurons. BDNF mediates the effects of activity and environmental conditions, allowing early perturbations to sculpt the performance of the adult sensory system. These findings emphasize the importance of sensory input during developmental stages.

\section{References}

Ahn M, Beacham D, Westenbroek RE, Scheuer T, Catterall WA (2007) Regulation of $\mathrm{Na}(\mathrm{v}) 1.2$ channels by brain-derived neurotrophic factor, TrkB, and associated Fyn kinase. J Neurosci 27:11533-11542.

An M, Luo R, Henion PD (2002) Differentiation and maturation of zebrafish dorsal root and sympathetic ganglion neurons. J Comp Neurol 446:267-275.

Barde YA (1994) Neurotrophins: a family of proteins supporting the survival of neurons. Prog Clin Biol Res 390:45-56.

Behar TN, Schaffner AE, Scott CA, Greene CL, Barker JL (2000) GABA receptor antagonists modulate postmitotic cell migration in slice cultures of embryonic rat cortex. Cereb Cortex 10:899-909.

Blader P, Plessy C, Strähle U (2003) Multiple regulatory elements with spatially and temporally distinct activities control neurogenin 1 expression in primary neurons of the zebrafish embryo. Mech Dev 120:211-218.

Blum R, Kafitz KW, Konnerth A (2002) Neurotrophin-evoked depolarization requires the sodium channel $\mathrm{Na}(\mathrm{V}) 1.9$. Nature 419:687-693.

Bolteus AJ, Bordey A (2004) GABA release and uptake regulate neuronal precursor migration in the postnatal subventricular zone. J Neurosci 24:7623-7631.

Bothwell M (1997) Neurotrophin function in skin. J Investig Dermatol Symp Proc 2:27-30.

Bruno MA, Cuello AC (2006) Activity-dependent release of precursor nerve growth factor, conversion to mature nerve growth factor, and its degradation by a protease cascade. Proc Natl Acad Sci U S A 103:6735-6740.

Carroll P, Lewin GR, Koltzenburg M, Toyka KV, Thoenen H (1998) A role for BDNF in machanosensation. Nat Neurosci 1:42-46.

Carvell GE, Simons DJ (1996) Abnormal tactile experience early in life disrupts active touch. J Neurosci 16:2750-2757.

Cermak SA, Daunhauer LA (1997) Sensory processing in the postinstitutionalized child. Am J Occup Ther 51:500-507.

Chien SQ, Li C, Li H, Xie W, Pablo CS, Zhang JM (2005) Sympathetic fiber sprouting in chronically cCompressed dorsal root ganglia without peripheral axotomy. J Neuropathic Pain Symptom Palliation 1:19-23.

Chung K, Chung JM (2001) Sympathetic sprouting in the dorsal root ganglion after spinal nerve ligation: evidence of regenerative collateral sprouting. Brain Res 895:204-212.

Clarke JD, Hayes BP, Hunt SP, Roberts A (1984) Sensory physiology, anatomy and immunohistochemistry of Rohon-Beard neurones in embryos of Xenopus laevis. J Physiol 348:511-525.

Coen L, du Pasquier D, Le Mevel S, Brown S, Tata J, Mazabraud A, Demeneix BA (2001) Xenopus Bcl-X(L) selectively protects Rohon-Beard neurons from metamorphic degeneration. Proc Natl Acad Sci USA 98:7869-7874.

Davies AM (1996) The neurotrophic hypothesis: where does it stand? Philos Trans R Soc Lond B Biol Sci 351:389-394.

Douglass AD, Kraves S, Deisseroth K, Schier AF, Engert F (2008) Escape behavior elicited by single, channelrhodopsin-2-evoked spikes in zebrafish somatosensory neurons. Curr Biol 18:1133-1137.

Fitzgerald M (2005) The development of nociceptive circuits. Nat Rev Neurosci 6:507-520.

Geremia NM, Pettersson LM, Hasmatali JC, Hryciw T, Danielsen N, Schreyer DJ, Verge VM (2010) Endogenous BDNF regulates induction of intrin- sic neuronal growth programs in injured sensory neurons. Exp Neurol 223:128-142.

Granato M, van Eeden FJ, Schach U, Trowe T, Brand M, Furutani-Seiki M, Haffter P, Hammerschmidt M, Heisenberg CP, Jiang YJ, Kane DA, Kelsh RN, Mullins MC, Odenthal J, Nüsslein-Volhard C (1996) Genes controlling and mediating locomotion behavior of the zebrafish embryo and larva. Development 123:399-413.

Hao MM, Moore RE, Roberts RR, Nguyen T, Furness JB, Anderson RB, Young HM (2010) The role of neural activity in the migration and differentiation of enteric neuron precursors. Neurogastroenterol Motil 22:e127-137.

Hapner SJ, Nielsen KM, Chaverra M, Esper RM, Loeb JA, Lefcort F (2006) NT-3 and CNTF exert dose-dependent, pleiotropic effects on cells in the immature dorsal root ganglion: neuregulin-mediated proliferation of progenitor cells and neuronal differentiation. Dev Biol 297:182-197.

Heinrich G, Pagtakhan CJ (2004) Both 5' and 3' flanks regulate zebrafish brain-derived neurotrophic factor gene expression. BMC Neurosci 5:19.

Heng JI, Moonen G, Nguyen L (2007) Neurotransmitters regulate cell migration in the telencephalon. Eur J Neurosci 26:537-546.

Huber K, Kuehnel F, Wyatt S, Davies AM (2000) TrkB expression and early sensory neuron survival are independent of endogenous BDNF. J Neurosci Res 59:372-378.

Humphrey T (1950) Intramedullary sensory ganglion cells in the roof plate area of the embryonic human spinal cord. J Comp Neurol 92:333-399.

Kim HJ, Na HS, Sung B, Nam HJ, Chung YJ, Hong SK (1999) Is sympathetic sprouting in the dorsal root ganglia responsible for the production of neuropathic pain in a rat model? Neurosci Lett 269:103-106.

Kollros JJ, Bovbjerg AM (1997) Growth and death of Rohon-Beard cells in Rana pipiens and Ceratophrys ornata. J Morphol 232:67-78.

Kuczewski N, Porcher C, Lessmann V, Medina I, Gaiarsa JL (2009) Activitydependent dendritic release of BDNF and biological consequences. Mol Neurobiol 39:37-49.

Lamborghini JE (1980) Rohon-Beard cells and other large neurons in Xenopus embryos originate during gastrulation. J Comp Neurol 189:323-333.

Lamborghini JE (1987) Disappearance of Rohon-Beard neurons from the spinal cord of larval Xenopus laevis. J Comp Neurol 264:47-55.

Lawson SN, Biscoe TJ (1979) Development of mouse dorsal root ganglia: An autoradiographic and quantitative study. J Neurocytol 8:265-274.

Lefcort F, Clary DO, Rusoff AC, Reichardt LF (1996) Inhibition of the NT-3 receptor TrkC, early in chick embryogenesis, results in severe reductions in multiple neuronal subpopulations in the dorsal root ganglia. J Neurosci 16:3704-3713.

LeMaster AM, Krimm RF, Davis BM, Noel T, Forbes ME, Johnson JE, Albers KM (1999) Overexpression of brain-derived neurotrophic factor enhances sensory innervation and selectively increase neuron number. J Neurosci 19:5919-5931.

Lesser SS, Sherwood NT, Lo DC (1997) Neurotrophins differentially regulate voltage-gated ion channels. Mol Cell Neurosci 10:173-183.

Li F, Li L, Song XY, Zhong JH, Luo XG, Xian CJ, Zhou XF (2009) Preconditioning selective ventral root injury promotes plasticity of ascending sensory neurons in the injured spinal cord of adult rats-possible roles of brain-derived neurotrophic factor, TrkB and p75 neurotrophin receptor. Eur J Neurosci 30:1280-1296.

Liebl DJ, Tessarollo L, Palko ME, Parada LF (1997) Absence of sensory neurons before target innervation in brain-derived neurotrophic factor-, neurotrophin 3- and TrkC-deficient mice. J Neurosci 17:9113-9121.

Lin SH, Cermak S, Coster WJ, Miller L (2005) The relation between length of institutionalization and sensory integration in children adopted from Eastern Europe. Am J Occup Ther 59:139-147.

Lum T, Huynh G, Heinrich G (2001) Brain-derived neurotrophic factor and $\operatorname{TrkB}$ tyrosine kinase receptor gene expression in zebrafish embryo and larva. Int J Dev Neurosci 19:569-587.

Luther JA, Birren SJ (2009) Neurotrophins and target interactions in the development and regulation of sympathetic neuron electrical and synaptic properties. Auton Neurosci 151:46-60.

Ma Q, Fode C, Guillemot F, Anderson DJ (1999) NEUROGENIN1 and NEUROGENIN2 control two distinct waves of neurogenesis in developing dorsal root ganglia. Genes Dev 13:1717-1728.

Martin SC, Marazzi G, Sandell JH, Heinrich G (1995) Five Trk receptors in the zebrafish. Dev Biol 169:745-758.

McGraw HF, Nechiporuk A, Raible DW (2008) Zebrafish dorsal root gan- 
glia neural precursor cells adopt a glial fate in the absence of neurogenin1. J Neurosci 28:12558-12569.

Metcalfe WK, Myers PZ, Trevarrow B, Bass MB, Kimmel CB (1990) Primary neurons that express the L2/HNK-1 carbohydrate during early development in the zebrafish. Development 110:491-504.

Novak AE, Taylor AD, Pineda RH, Lasda EL, Wright MA, Ribera AB (2006) Embryonic and larval expression of zebrafish voltage-gated sodium channel alpha-subunit genes. Dev Dyn 235:1962-1973.

Patel TD, Jackman A, Rice FL, Kucera J, Snider WD (2000) Development of sensory neurons in the absence of NGF/TrkA signaling in vivo. Neuron 25:345-357.

Petersson P, Granmo M, Schouenborg J (2004) Properties of an adult spinal sensorimotor circuit shaped through early postnatal experience. J Neurophysiol 92:280-288.

Pierre K, Dupouy B, Allard M, Poulain DA, Theodosis DT (2001) Mobilization of the cell adhesion glycoprotein F3/contactin to axonal surfaces is activity dependent. Eur J Neurosci 14:645-656.

Pineda RH, Heiser RA, Ribera AB (2005) Developmental, molecular, and genetic dissection of $\mathrm{I}_{\mathrm{Na}}$ in vivo in embryonic zebrafish sensory neurons. J Neurophysiol 93:3582-3593.

Pineda RH, Svoboda KR, Wright MA, Taylor AD, Novak AE, Gamse JT, Eisen JS, Ribera AB (2006) Knockdown of Nav1.6a $\mathrm{Na}^{+}$channels affects zebrafish motoneuron development. Development 133:3827-3836.

Purves D, Snider WD, Voyvodic JT (1988) Trophic regulation of nerve cell morphology and innervation in the autonomic nervous system. Nature 336:123-128.

Reyes R, Haendel M, Grant D, Melancon E, Eisen JS (2004) Slow degeneration of zebrafish Rohon-Beard neurons during programmed cell death. Dev Dyn 229:30-41.

Ribera AB, Nüsslein-Volhard C (1998) Zebrafish touch-insensitive mutants reveal an essential role for the developmental regulation of sodium current. J Neurosci 18:9181-9191.

Schinder AF, Poo M (2000) The neurotrophin hypothesis for synaptic plasticity. Trends Neurosci 23:639-645.

Sebert ME, Shooter EM (1993) Expression of mRNA for neurotrophic factors and their receptors in the rat dorsal root ganglion and sciatic nerve following nerve injury. J Neurosci Res 36:357-367.
Shinder V, Govrin-Lippmann R, Cohen S, Belenky M, Ilin P, Fried K, Wilkinson HA, Devor M (1999) Structural basis of sympatheticsensory coupling in rat and human dorsal root ganglia following peripheral nerve injury. J Neurocytol 28:743-761.

Svoboda KR, Linares AE, Ribera AB (2001) Activity regulates programmed cell death of zebrafish Rohon-Beard neurons. Development 128:3511-3520.

Tam T, Mathews E, Snutch TP, Schafer WR (2000) Voltage-gated calcium channels direct neuronal migration in Caenorhabditis elegans. Dev Biol 226:104-117.

Tong XP, Li XY, Zhou B, Shen W, Zhang ZJ, Xu TL, Duan S (2009) Ca $\left({ }^{2+}\right)$ signaling evoked by activation of $\left.\mathrm{Na}^{+}\right)$channels and $\mathrm{Na}\left({ }^{+}\right) / \mathrm{Ca}\left({ }^{2+}\right)$ exchangers is required for GABA-induced NG2 cell migration. J Cell Biol 186:113-128.

Valdés-Sánchez T, Kirstein M, Pérez-Villalba A, Vega JA, Fariñas I (2010) BDNF is essentially required for the early postnatal survival of nociceptors. Dev Biol 339:465-476.

Westerfield M (1995) The Zebrafish book: a guide for the laboratory use of zebrafish (Brachydanio rerio). Eugene, OR: University of Oregon.

Williams JA, Barrios A, Gatchalian C, Rubin L, Wilson SW, Holder N (2000) Programmed cell death in zebrafish rohon beard neurons is influenced by TrkC1/NT-3 signaling. Dev Biol 226:220-230.

Wright DE, Snider WD (1995) Neurotrophin receptor mRNA expression defines distinct populations of neurons in rat dorsal root ganglia. J Comp Neurol 351:329-338.

Wright MA, Mo W, Nicolson T, Ribera AB (2010) In vivo evidence for transdifferentiation of peripheral neurons. Development 137: 3047-3056.

Wu YJ, Krüttgen A, Möller JC, Shine D, Chan JR, Shooter EM, Cosgaya JM (2004) Nerve growth factor, brain-derived neurotrophic factor, and neurotrophin- 3 are sorted to dense-core vesicles and released via the regulated pathway in primary rat cortical neurons. J Neurosci Res 75:825-834.

Zhang JM, Strong JA (2008) Recent evidence for activity-dependent initiation of sympathetic sprouting and neuropathic pain. Sheng Li Xue Bao 60:617-627. 